\title{
Proactive Management Transportation Logistics Infrastructure Life-Cycle (Digital Transformation)
}

\author{
Alexey Nekrasov $^{1}$, and Anna Sinitsyna ${ }^{1 *}$ \\ ${ }^{1}$ Russian University of Transport (MIIT), 9b9 Obrazcova str., Moscow, 127994, Russia
}

\begin{abstract}
The paper considers an innovative approach to life-cycle management of transportation-logistical infrastructure, basing on proactive management concept. It recommends new processes, providing for sustainability and adaptation of complex organisational-technical objects in digital transformation of Industry 4.0. Highly-effective infrastructure is based on coordinated interaction of enterprises at different stages of the lifecycle «design - operation - monitoring and correction».
\end{abstract}

\section{Introduction}

The basis of assessing efficiency of infrastructure in the new technological paradigm is a new criteria - that is providing for adaptivity of transportation system and its infrastructure. The prevailing model of innovative economy of the XXI century states are complex organisational-technical objects (COTOs), oriented towards combination of informational technologies and integrated models of life-cycle of different systems of an enterprise [7].

Traditional (functional) logistics, dealing with placement of production, warehouses, customers and modeling supply chains with the aim of optimizing costs and order time, in modern conditions implies refocusing to adaptive-digital methods. A new approach is required, the one based on the system mechanism of integrated management not only in supply chains, but also that of processes in an enterprise basing on the interaction of intelligent and the Internet technologies (the Intenet-of-things type)

\section{Material and Methods}

The systems, means and complexes used are usually characterized by multi-dimensionality, multi-structuralism, indefiniteness of functioning, hierarchy, excessive elements and connections, variety of implementing functions and processes and mobility of components Higher complexity of the existing COTOs requires more controlled parameters charactering functioning processes. Research and practical experience show that managerial delays and mistakes as well as incorrect process monitoring can lead to serious negative consequences. All of this largely depends on the level of sustainability of logistical processes, which provide for the efficiency of the main elements of the system (production) for the whole life-cycle of both the production and infrastructure. [1-5].

* Corresponding author: acc-lgkr@mail.ru 
In modern conditions the infrastructure of the life-cycle of transportation-logistics system can provide for conditions of innovative development, forming the demand for robot-oriented loading and transportation equipment and modern technological solutions, including logistic engineering and transport construction.

For example, it is impossible to imagine system approach implementation at railway transport without logistic engineering in warehousing, commercial operation Effective functioning of any system requires integration, which will define interaction of different companies, logistic operators in the common system passenger and freight services (fig. 1), and the possible changes of each element (network configuration, rolling-stock type, transport mode) should be considered in connection with other transport modes [6].

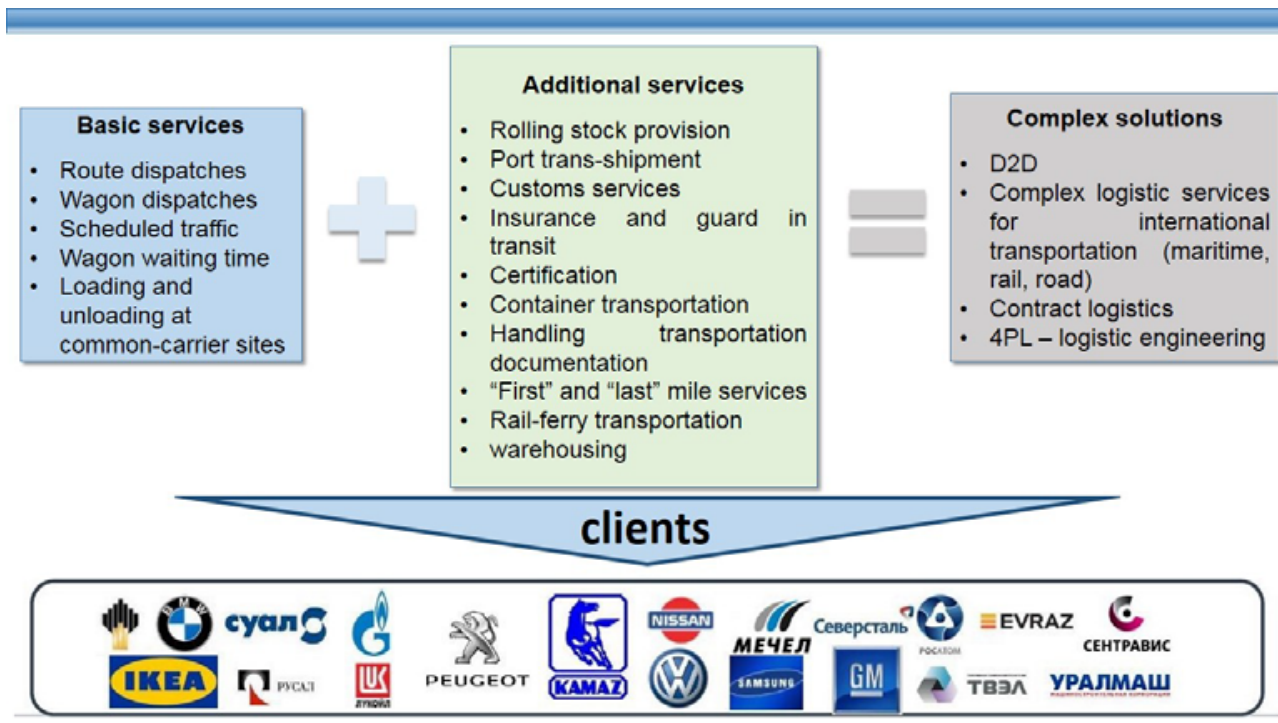

Fig. 1. Freight services of JSC Russian Railways.

It is important to bear in mind that lack of resources (caused by a number of objective and subjective reasons) makes it impossible to keep up the required operational level of modern COTOs, which are to be usable in cases of faults, accidents and disasters and thus are to be sustainable. For this purpose it is possible to recommend new methods of proactive management, which are accompanied by intentional reconfiguration of COTOs and provide a complex system forecast and higher efficiency, basing on a large array of electronic data. Proactive management connects a physical object (infrastructure) with COTO's life-cycle processes by means of digital information-communication technologies (ICT) [7].

Proactive COTO infrastructure management unlike traditionally used reactive management (aimed at operative reaction and further avoidance of incidents) implies prevention of incidents basing on creating in a monitoring and managerial system principally new forecasting and preventing opportunities in formation and implementation of managerial activities basing on system (complex) modelling [8-10].

Now there are various types of organizing proactive monitoring and COTO management, including proactive technologies of managing structural dynamics of managing the objects concerned. These technologies include: changing ways and aims of COTO functioning, their content, operational sequence in various conditions, relocating elements and subsystems of COTOs, redistribution and decentralization of functions, tasks, management algorithms, information flows between COTO levels, using flexible (shortcut) technologies of COTO management, structural reconfiguration of COTOs in case of degradation [11,12]. 


\section{Theoretical approach and implementation}

Proactive (preventive) monitoring and management technologies in a COTO can be considered as prospective technologies in managing complexity of compound systems (transportation-logistic objects), thanks to which the objects remain sustainably operational at carrying out tasks in the forecast conditions to the required degree.

Modern development of international transportation and progressive transportationlogistics technologies implies using several transport modes with its interaction with different life-cycle stages, that characterizes a transport system as capable of effective cooperation due to geographical and functional diversification and autonomy of separate supply chain stages. Introduction of modern technologies, including new through digital technologies in the near future will be aimed not only a cutting costs, increasing reliability and safety of all stages, but also at mobile compatibility of transportation life-cycle processes.

High efficiency of transport is directly linked to both structure (processes) of enterprises, and the equipment and production assets used, which are employed at different life-cycle stages of systems. All this increases complexity of COTOs, which include transportation and transportation-logistics services. [13,14].

Each transportation-logistics system is based not only o using new transportation technologies at a single enterprise of a network, dealing with receiving, handling and delivery to the final customer, but also on the creation of numerous models of sustainable interaction life-cycle. Integration of transportation-logistics processes and production assets included into infrastructure (terminals, warehouses, lifting and transportation equipment, rollingstock, etc) provides for higher growth of the productivity of the whole system, and not single employees and workstations.

Thus methodology, technological solutions and tools of organizational interaction based on proactive management should be based on integrated new generation transportationlogistic systems (ITLS) combining subsystems of transportation-logistics services, supply stages and provide sustainability and client orientation at a more efficient level. That is one of the priorities of cyber-physical systems, provided for in the strategy of the industry 4.0 $[15,16]$.

The formation and introduction of high-quality and complex system of freight handling based on the integration of transport network members is to be based on adaptivity, safety and sustainability. A highly-effective ITLS is based on coordination and interaction of enterprises at the life-cycle stages "design - operation- operational control - check-up and correction-management system monitoring". This framework forms the life-cycle processes of proactive management. This direction is aimed at providing not only sustainability of transport, but also competitive infrastructure of Russian national economy. Possibly types of COTO stages based on structural dynamics methodology are presented in figure 2.

Thus, a task is set and solved not only to cut expenses at each stage of a supply chain, but also to carry out a complex assessment of transportation-logistics infrastructure. Due to this a balance should be found between stability (equilibrium) and reconfiguration of processes between different life-cycle models shown in figure 2 [17].

New technological framework known as Industry 4.0 provides for further integration of a network of machines that will be able to autonomously change production patterns, keeping up high efficiency. The increased integration of «intelligent» works into industrial and transport infrastructure will mean much lower energy consumption and higher labour productivity.

The creation of digital technologies M2M (Machine-to-Machine) and IoT (Internet of Things) will enable logistic companies to develop supply chain management systems and enterprise management systems via machine interaction technologies [18]. M2M-technology 
enables a remote device to transmit to the data processing centre the data about a monitored object - COTO.

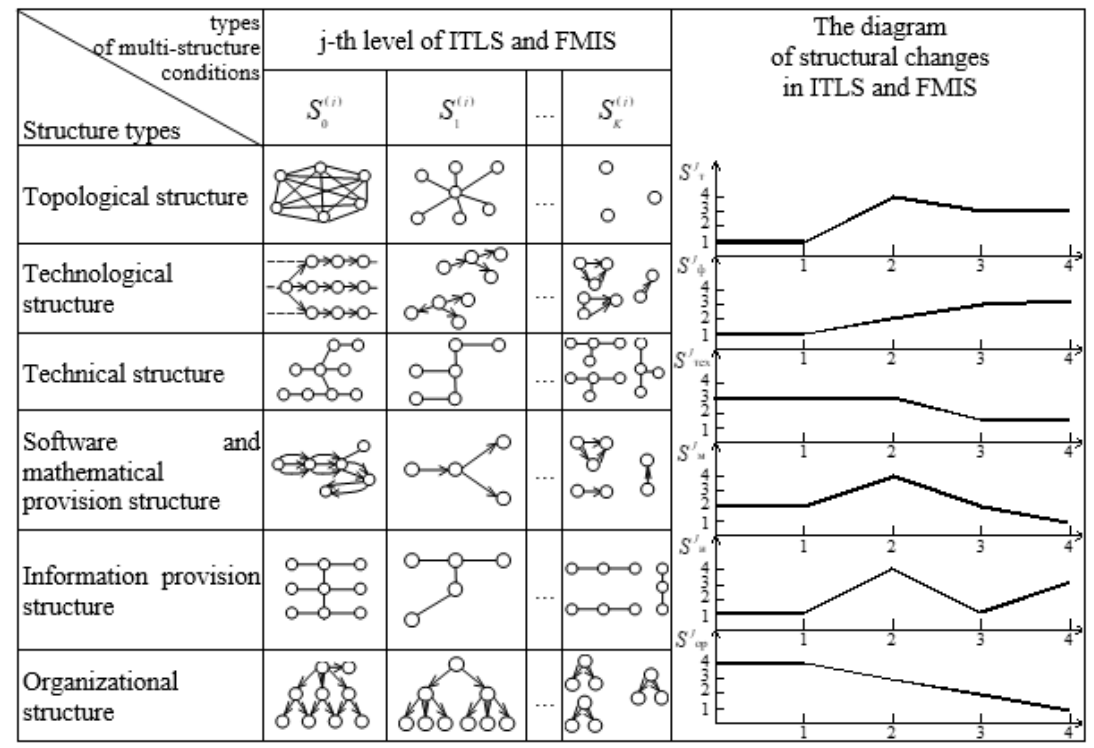

Fig. 2. Structure types in structure dynamics.

\section{Results and Discussion}

However, the main challenge is not to increase information volume and automation via cyberphysical (robot-oriented) systems, but to form the management of self-governance, which is the most effective way to resist uncertainty (risks) of the environment), to support COTO's structures and functions in new models of life-cycle management. That is why the priority directions in digital transformation of the IT sphere are the strategy of adaptive and proactive systems, adaptive management and adaptive enterprise [19]. The priority of the range of tools in such systems and enterprises is improving the life-cycle management processes. Under these conditions the efficiency will first of all depend on its success in developing innovative technologies and adaptive enterprises (figure 3 ).

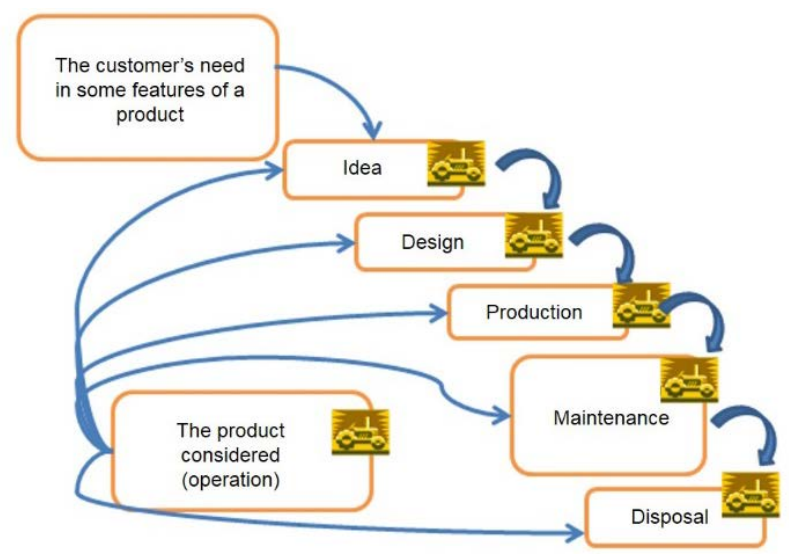

Fig. 3. Infrastructure equipment life-cycle transformation. 


\section{Conclusion}

Thus, when considering the problem of transformation of integrated transportation-logistical systems in to "digital" industry, it is necessary to create a new image and features of ITLS, which should comply with global changes taking place in the modern world, based on the Industry 4.0 strategy and proactive management. It will create the conditions for adapting transportation-logistical infrastructure to the modern service-oriented sphere of the Russian economy.

New COTO-forming principles should be aimed at national security and sustainable transport development. The priority among business models of "knowledge economy" and logistical technologies should go to ITLS life-cycle management models with a long timeline. One of the main ideas of life-cycle management systems in effective use of consistent system presentation and its environment in initially incompatible organizational-technical systems of «larger organization».

\section{References}

1. J Markard, The life cycle of technological innovation systems, Technological Forecasting and Social Change, Article in press, https://doi.org/10.1016/j.techfore.2018.07.045. (2018)

2. A. Nekrasov, A. Sinitsyna, Logistic engineering as a tool for integration of logistics systems // Logistics, № 12. - p. 40-45. (2016)

3. E. Oigman, E. Popov. Business reengineering. Reengineering organizations and information technology. - Moscow: Finance and Statistics, 336 p. (1997)

4. C. Prinz, N. Kreggenfeld, B. Kuhlenkötter (2018), Lean meets Industrie 4.0 - a practical approach to interlink the method world and cyber-physical world. In: Procedia Manufacturing, 23, 21-26. DOI: 10.1016/j.promfg.2018.03.155 (2018)

5. R. Neugebauer, S. Hippmann, M. Leis, M. Landherr, Industrie 4.0 - From the Perspective of Applied Research. In: Procedia CIRP 57, 2 - 7. DOI: 10.1016/j.procir.2016.11.002 (2016)

6. About priority directions of development of transport and logistics business of the holding «RZD». Transformation of the business model of the holding «RZD». [Electronic resource]. - URL: http://cargo.rzd.ru (reference date is September 19, (2017)

7. F. Zezulka, P. Marcon, Z. Bradac, J. Arm, I. Vesely, Communication Systems for Industry 4.0 and the IIoT. ScienceDirect, IFAC PapersOnLine 51-6. 150-155. DOI: 10.1016/j.ifacol.2018.07.145. (2018)

8. V. Kalinin, B. Sokolov, A multi-model approach to the description of control processes of space vehicles // Theory and control systems, No. 1. - p. 56-61. (1995)

9. M. Okhtilev, B. Sokolov, R. Yusupov, Theoretical and technological foundations of the concept of proactive monitoring and management of complex objects // ScientificTechnical and Applied Journal «Izvestiya SFU. Technical science». Section V. Systems and control points.- №1. - p. 162-174. [Electronic resource]. - URL: http://izvtn.tti.sfedu.ru/?page_id=1576 (2015).

10. R. Yusupov, B. Sokolov, Problems of the development of cybernetics and informatics at the present stage // Collection «Cybernetics and Informatics». - St. Petersburg: Publishing house SPbSPU, p. 6 - 21. (2006) 
11. E. Tantik, R. Anderl, Potentials of the Asset Administration Shell of Industrie 4.0 for Service-Oriented Business Models. In: Procedia CIRP 64. 363 - 368. DOI: 10.1016/j.procir.2017.03.009 (2017)

12. M.A.Munira, R.J. Rahul, O. Neil, S. Barry, A product life cycle ontology for additive manufacturing, Computers in Industry, 105. 191-203. - URL: https://doi.org/10.1016/j.compind.2018.12.007 (2019)

13. Engineering logistics: logistic-oriented product lifecycle management. Textbook for high schools. / L. Mirotin, I. Omelchenko, A. Kolobov and others; Ed. L. Mirotina and I. Omelchenko. - M .: Hot line - Telecom, 644 p. (2011)

14. A. Kartashev, A. Nekrasov, K. Atayev, Life cycle management of complex high technology products in integrated supply chains: monograph. - M .: PrintUp, 324 p. (2016)

15. K. Meyer, S. Davis, Live organization. Trans with English. - Moscow: Publishing house «Good Book», 368 p. (2007)

16. A. Issa, B. Hatiboglu, A. Bildstein, T. Bauernhansl, Industrie 4.0 roadmap: Framework for digital transformation based on the concepts of capability maturity and alignment. In: Procedia CIRP 72 973-978. DOI: 10.1016/j.procir.2018.03.151 (2018)

17. A. Nekrasov, A. Sinitsyna, Transformation of integrated transport and logistics systems into the digital industry // Logistics, № 8. - p. 36 - 41. (2007)

18. A. Tsivlin, From M2M to IoT: evolution through synergy // Logistics, № 12. - p. 40 45. (2015)

19. St. Bir, The brain of the firm. - Moscow: URSS, 315 p. (2005) 